\section{Remediation: where does the responsibility lie?}

\author{
Tim Swanwick, Julia Whiteman
}

Twelve years after it was first proposed by the General Medical Council (GMC), December 2012 sees the introduction of 'revalidation' for all doctors in the UK. This 5-yearly affirmation of fitness to practise builds on existing legislation assigning every doctor to a 'responsible officer' (RO) and laying out a set of expectations in relation to professional development and performance review. ${ }^{1}$ Revalidation is founded on a strengthened appraisal processes covering the full scope of work for which a doctor holds their licence to practise, and a closer link with clinical governance systems. For doctors in postgraduate training, the Annual Review of Competence Progression is also being enhanced to ensure it covers revalidation requirements. Inevitably, the evolving system has led to questions about how those that are falling short of the required professional standards can be helped to meet them. In other words, what in the way of remediation needs to be made available, how can it be provided efficiently and effectively, and where does the responsibility for such provision lie?

\section{WHAT IS REMEDIATION?}

Remediation describes the process through which doctors' performance concerns can be addressed to facilitate a return to safe practice. Performance concerns can be identified at any career stage and it is uncertain which methods of screening are most effective. As such the prevalence of underperformance in doctors across the UK is unknown. Currently, resources for remediation are typically concentrated on the small proportion of doctors identified through complaints to the GMC and National Clinical Assessment Service (NCAS) and whose problems are likely to be at the more severe end of the spectrum.

Remediation was the focus of a recent Department of Health steering group report, ${ }^{2}$ which adopted a definition of remediation as:

Professional Development, London Deanery, London, UK

Correspondence to Dr Tim Swanwick, Postgraduate Dean, London Deanery, Stewart House, 32 Russell

Square, London WC1B 5DN, UK;

tim.swanwick@londondeanery.ac.uk the overall process agreed with a practitioner to redress identified aspects of underperformance. Remediation is a broad concept varying from informal agreements to carry out some reskilling to more formal supervised programmes of remediation or rehabilitation.

The new processes will inevitably identify some doctors who fall outside the standards set down in Good Medical Practice $^{3}$ and for whom, if they are to revalidate, some form of remediation will be needed. Under the RO regulations, every doctor in the UK will have a designated body, and each designated body an RO. Among the responsibilities listed for the $\mathrm{RO}$ are a number that relate to remediation, including ensuring that appropriate action is taken in response to concerns about a practitioner's conduct or performance, including an obligation to:

identify concerns and ensure that appropriate measures are taken to address these, including but not limited to:

(i) requiring the medical practitioner to undergo training or retraining

(ii) offering rehabilitation services

(iii) providing opportunities to increase the medical practitioner's work experience

Since the above reports were written, the NHS structures in which these processes are occurring have developed, particularly in England. The establishment of Health Education England and it's Local Education and Training Boards (LETBs) provides an opportunity to commission remediation support within a LETB geography in order to strengthen local processes and ensure that ROs have access to specialist support services and are thereby able to fulfil their legal obligations as set out above.

\section{WHERE DOES THE RESPONSIBILITY FOR REMEDIATION LIE?}

It is a fundamental duty of a registered medical practitioner to ensure that they have the skills and competences necessary to undertake the responsibilities for which they hold a licence to practise. Under revalidation requirements, it is also a licensed doctor's duty to ensure that they provide the supporting information to enable their RO to make a positive revalidation recommendation to the GMC.

The Department of Health's White Paper Liberating the NHS: Developing the Healthcare Workforce ${ }^{4}$ lays the responsibility for continuing professional development (CPD) with employers.

The RO legislation makes it a duty for ROs to ensure that doctors are appropriately trained and supported in the range of roles they fulfil across the scope of their practice and that remediation is available to address any causes for concern.

This represents a three-way split of responsibilities that has patient safety at the heart and with doctors themselves playing a lead role in planning how to meet their developmental needs, respond to causes of concern, and access support that is made available to them through their employers and/or designated bodies.

\section{WHAT SORT OF REMEDIATION IS REQUIRED?}

The determinants of clinical performance are complex, multifactorial and interconnected. ${ }^{5}$ Remediation therefore often requires that a number of issues are addressed simultaneously, namely in the domains of:

- health (bio-psycho-social)

- clinical competence

- personality and behaviour

- the organisational context

The aim of remediation is, where appropriate, to restore doctors to their full range of practice without at any stage compromising patient safety. However, it may be mutually more acceptable to reach a compromise between the doctor and their RO, employer or contractor around a reduced scope of practice to ensure safe practice and practitioner well-being.

Remediation action plans should be individually negotiated and agreed in writing between the employer and the practitioner and, for doctors in postgraduate training, their postgraduate dean. They should include specific goals, objectives and time scales, and be subjected to periodic review by the RO or their nominated deputy. All aspects of performance including clinical knowledge, skills, health, behaviour and context should be addressed within a single action plan. Occupational health services should be involved in any situation where the doctor's health is, or has contributed to, the need for a remediation programme. Human resources' advice and input should be sought for any concerns relating to conduct or behaviour.

Other remediation interventions that it may be helpful to consider include: 
- specialist careers guidance and support

- clinical placements to address a general or specific clinical need

- retraining programmes

- language and communication skills training

- coaching and mentoring

- complex case management after GMC and/or NCAS assessment

- specialist psychological and addiction support

At the end of any remediation programme-that is, when deficits in good medical practice have been remediedthere should be a period of rehabilitation back to unsupervised practice. During this period, specific attention should be paid to any re-emergence of issues that might have contributed to the original problem.

The evidence base for effective remediation is thin. Equally there are many anecdotal stories illustrating when remediation has not brought about the desired changes in clinical performance. From our experience, there are a number of reasons why remediation might not work:

- learning needs are poorly matched to resources without taking into account individual needs and circumstances

- what is offered is limited to the availability of local resources and idiosyncratic interest rather than holistic need

- objectives, including desired outcomes, are not mutually agreed

- information from reviews conducted throughout the remediation phase are not factored into ongoing planning

- contributing systemic organisational issues are not factored into remediation and rehabilitation planning

\section{HOW COULD REMEDIATION BE PROVIDED?}

The 2011 Department of Health report on remediation recommends that 'performance problems, including clinical competence and capability issues, should normally be managed locally wherever possible'. This is a sensible principle because of the location of both the employment and RO responsibilities. However, the report identifies that, in the organisations surveyed, it was still an area that many employers and contracting bodies found difficult to manage. Providing suitable remediation packages was also challenging' (p2).

Successful remediation requires the sourcing of expert specialist input-for example, around careers, mental health, communication skills-to a level that is not readily available even within the largest provider organisation. In primary care, such provision is even harder to identify. Furthermore, it may be necessary to identify remedial placements outside the provider institution. Again, local management of such out-placements is difficult. In addition, those managing local remediation on an infrequent or ad hoc basis are likely to run into issues of patient safety and legal challenge. There is here a question of economy of scale, both of expertise and experience, in providing a consistent approach to remediation and support to the service.

So, to manage remediation locally requires expert input and placement support. How should this be provided? There are a number of options, ranging from the direct contracting of employers with private providers to the commissioning of a 'regional' professional support service, either privately provided or established within the NHS structures. In each case, if remediation is considered to be a form of CPD, the commissioning agency (in England at least) would be the LETB acting on behalf of employers.

\section{THE PROFESSIONAL SUPPORT UNIT (PSU)-A WAY FORWARD?}

Another recent report on remediation, this time by the Academy of Medical Royal Colleges, ${ }^{6}$ recommends the establishment of a dedicated service to support individuals, employers and ROs:

\begin{abstract}
The working group supports the proposal to establish Professional Support Units at a regional level to manage and coordinate programmes of remediation, drawing on the expertise of other organisations as and when required (p19)
\end{abstract}

There would be distinct advantages to the establishment of such a service mapped to a LETB geography. In many areas of the country, a professional support service is already in place, enabling deaneries and other provider organisations to discharge their existing responsibilities to doctors in postgraduate training and those practitioners with GMC conditions and undertakings. The aim of a professional support service is not to take on the $\mathrm{RO}$ or employer role but to provide the concentration of expertise necessary to manage remediation safely and effectively.

The location of such a service could be with a lead employer, an independent organisation, private company or social enterprise or within existing deanery structures as they are transfigured. The additional advantage of centring provision on existing offerings within postgraduate deaneries, or their successors within LETBs, is that they administer a network of training placements and already have a network of expertise whose remit could easily be extended.

Logically, a PSU could serve the needs of its LETB (or group of LETBs) RO population including the postgraduate dean. Services would be purchased by employers, ROs or individuals depending on training and employment status of the individual. A support unit could also offer resources across the multiprofessional landscape of healthcare including into the independent sector and health service management.

Although in theory, a PSU may be privately owned and managed, in view of the access to remedial supervised placements, the most appropriate place to host a PSU may be alongside other deanery functions and separate from employing bodies.

Thought still needs to be given to how such services are funded. If one follows the principle of the beneficiary paying, then funding will vary according to workforce pressures in areas where it is more difficult to recruit. But employer and designated body responsibilities require access to remediation and CPD. This implies that funding will need to be apportioned between NHS Commissioning Board and Health Education England to fund the provision of remediation and the commissioning of placements.

\section{CONCLUSION}

Revalidation has been a long time in the making. For patients, the public and the profession, this is probably a good thing. The establishment of an explicit process for the maintenance of a licence to practiceaccompanied by professional and legal expectations-should mean that performance problems are identified early. Once issues surface though, they will need to be dealt with efficiently and effectively, and this will require robust pathways to support doctors who, perhaps through no fault of their own, find themselves in need of additional professional support. The PSU is one possible model to ensure that ready access to remediation is available. Whether a cash-stripped NHS can commit to its provision is yet to be seen. Equally the question has to be asked: can it afford not to?

Funding None. 
Disclaimer The authors are members of the Department of Health (England) working group on remediation. Where there are views expressed in this paper, they are the authors' own.

Competing interests None.

Provenance and peer review Commissioned; internally peer reviewed.

To cite Swanwick T, Whiteman J. Postgrad Med J 2013, 89, 1-3.

Postgrad Med J 2013;89:1-3.

doi:10.1136/postgradmedj-2012-131642

\section{REFERENCES}

1 The Medical Profession (Responsible Officers) Regulations. UK, 2010.

2 Department of Health. Report of the Department of Health Steering Group on Remediation. 2011. http:// www.dh.gov.uk/en/ (accessed 13 November 2012).

3 General Medical Council. Good Medical Practice. London: General Medical Council, 2009.

4 Department of Health. Liberating the NHS: Developing the Healthcare Workforce. 2010. http://www.dh.gov. uk/prod_consum_dh/groups/dh_digitalassets/@dh/@ en/documents/digitalasset/dh_122934.pdf (accessed 13 November 2012).
5 Cohen D, Rhydderch, Cooper I. Managing remediation. In: Swanwick T. ed. Understanding medical education. Oxford: Wiley-Blackwell, 2010:366-78

6 Academy of Medical Royal Colleges Remediation Working Group. Remediation Working Group Report. 2012. http://www.aomrc.org.uk/publications/ statements/doc_view/63-remediation-and-revalidation. html (accessed 13 November 2012). 